\title{
O subproduto do corante caramelo IV em alimentos pode causar toxicidade?
}

\author{
Can the by-product of the caramel color IV in food promove toxicity? \\ Puede el subproducto del colorante de caramelo en los alimentos causar toxicidad?
}

Recebido: 24/06/2021 | Revisado: 30/06/2021 | Aceito: 06/07/2021 | Publicado: 16/07/2021

\author{
Nayara Resende Gomes \\ ORCID: https://orcid.org/0000-0002-4468-7241 \\ Universidade Federal de Ouro Preto, Brasil \\ E-mail: nayara.gomes@aluno.ufop.edu.br \\ Melina Oliveira de Souza \\ ORCID: https://orcid.org/0000-0001-5883-556X \\ Universidade Federal de Ouro Preto, Brasil \\ E-mail: melina@ufop.edu.br \\ Camila Carvalho Menezes \\ ORCID: https://orcid.org/0000-0002-6709-8706 \\ Universidade Federal de Ouro Preto, Brasil \\ E-mail: camilamenezes@ufop.edu.br
}

\begin{abstract}
Resumo
O corante caramelo tem sido amplamente utilizado em alimentos e bebidas e é regulamentado globalmente como aditivo químico. As quatro classes distintas do corante caramelo (caramelo simples (I), caramelo sulfito (II), caramelo de amônia (III) e caramelo sulfito-amônia (IV)) são bem caracterizadas e cada uma tem especificidades que variam com os tipos de processamento do composto, especialmente a adição de reagentes que podem dar origem a compostos de baixo peso molecular, como por exemplo, o 4-metilimidazol, subproduto do caramelo IV, que pode ter significativo efeito toxicológico. Tendo em vista o elevado consumo de alimentos industrializados e a potencial exposição em longo prazo desse composto, em diferentes faixas etárias, o objetivo desta revisão foi resumir os estudos mais relevantes disponíveis nos últimos 5 anos sobre os efeitos tóxicos do 4-metilimidazol, nas bases de dados PubMed, Science Direct e Lilacs. Os resultados dos estudos avaliados são divergentes e os mecanismos de toxicidade ainda não estão bem elucidados, apesar de alguns estudos terem encontrado efeitos negativos à saúde com a exposição ao 4-metilimidazol, tornando-se relevante novos estudos para esclarecer a sua real segurança.
\end{abstract}

Palavras-chave: Aditivo alimentar; Corante de alimentos; 4-metilimidazol; Efeitos adversos.

\begin{abstract}
Caramel coloring has been widely used in foods and beverages and is globally regulated as a chemical additive. The four distinct classes of caramel dye (simple caramel (I), sulfite caramel (II), ammonia caramel (III) and sulfite-ammonia caramel (IV)) are well characterized and each has specificities that vary with the types of processing of the compound, especially the addition of reagents that can give rise to low molecular weight compounds, such as 4-methylimidazole, a by-product of caramel IV, which can have a significant toxicological effect. In view of the high consumption of processed foods and the potential long-term exposure of this compound, in different age groups, the aim of this review was to summarize the most relevant studies available in the last 5 years on the toxic effects of 4-methylimidazole, in the bases PubMed, Science Direct, and Lilacs databases. The results of the evaluated studies are divergent and the mechanisms of toxicity are not well elucidated, although some studies have found negative health effects with exposure to 4-methylimidazole, making further studies relevant to clarify its real safety.
\end{abstract}

Keywords: Food additive; Food coloring; 4-methylimidazole; Adverse effects.

\section{Resumen}

El colorante de caramelo se ha utilizado ampliamente en alimentos y bebidas y está regulado a nivel mundial como aditivo químico. Las cuatro clases distintas de tinte de caramelo (caramelo simple (I), caramelo de sulfito (II), caramelo de amoniaco (III) y caramelo de sulfito de amoniaco (IV)) están bien caracterizadas y cada una tiene especificidades que varían con los tipos de procesamiento compuesto, especialmente la adición de reactivos que pueden dar lugar a compuestos de bajo peso molecular, como el 4-metilimidazol, un subproducto del caramelo IV, que puede tener un efecto toxicológico significativo. En vista del alto consumo de alimentos procesados y la potencial exposición a largo plazo de este compuesto, en diferentes grupos de edad, el objetivo de esta revisión fue resumir los estudios más relevantes disponibles en los últimos 5 años sobre los efectos tóxicos de 4- metilimidazol, en las bases de datos PubMed, Science Direct y Lilacs. Los resultados de los estudios evaluados son divergentes y los mecanismos de toxicidad no están bien esclarecidos, aunque algunos estudios han encontrado efectos negativos para la salud con la exposición al 4 metilimidazol, lo que hace relevantes estudios adicionales para aclarar su seguridad real.

Palabras clave: Aditivo alimentario; Colorante alimenticio; 4-metilimidazol; Efectos adversos. 


\section{Introdução}

A humanidade tem buscado diferentes métodos para melhorar aspectos dos alimentos. Adicionar substâncias para melhorar a aparência, o sabor ou para aumentar o tempo de preservação dos alimentos é uma das técnicas frequentemente utilizadas. A consequência é o surgimento de um problema: a qualidade e a segurança dos alimentos que contém aditivos químicos. Ente eles, o caramelo é um dos aditivos mais consumidos mundialmente e é produzido a partir do aquecimento de carboidratos de fontes vegetais (glicose, sacarose, açúcar invertido, etc.) na presença de promotores da caramelização, o resultado é uma mistura complexa que é responsável pelas propriedades aromáticas e corantes dos caramelos (Mateo-Fernández et al., 2019).

O caramelo IV (INS 150d) é um subgrupo dos caramelos feito pelo aquecimento controlado de carboidratos na presença de sulfitos e compostos de amônia (Ashurst et al., 2017). Este caramelo é usado como corante em produtos de panificação, misturas para bolos, doces, refrigerantes a base cola e outras bebidas ácidas, xaropes para panquecas, rações para animais, temperos secos, entre outros. Apresenta coloração marrom e contém partículas coloidais com cargas negativas (BeMiller, 2018).

O 4-metilimidazol (4-MEI) é um subproduto indesejável produzido durante processo de caramelização dos corantes caramelo de classe III (caramelo amônia) e classe IV (caramelosulfito-amônia) e é detectado em níveis potencialmente tóxicos em alguns alimentos, como refrigerantes de cola (Smith et al., 2015). Também é encontrado em outras bebidas (chá gelado, whisky, bebidas de malte, cervejas escuras) e produtos alimentícios (molhos, xaropes, sobremesas lácteas, etc.) que contém esses corantes (Smith et al., 2015). Além disso, é encontrado no café, cacau e alimentos torrados em que 4-MEI é formado como um subproduto do escurecimento não enzimático durante o tratamento térmico (Folmer et al., 2018). Dessa forma, podemos observar que a população em geral, incluindo crianças e adolescentes, está exposta diariamente ao 4-MEI na dieta (Behl et al., 2020).

Internacionalmente, o uso do corante caramelo IV em bebidas não alcoólicas é permitido como aceitável dentro do limite máximo de $50.000 \mathrm{mg} / \mathrm{Kg}$, ou seja, até $5 \%$ do produto. Este limite foi estabelecido pela Comissão do Codex Alimentarius em 2009, e consta da sua Norma Geral de Aditivos Alimentares - GSFA, o Codex STAN 192/1995, para a categoria 14.1.4. Water-based flavoured drinks, including "sport," "energy, " or "electrolyte" drinks and particulated drinks (Codex Alimentarius, 2019).

A ANVISA (Agência Nacional de Vigilância Sanitária) mantém o caramelo IV na legislação brasileira com base nos estudos do JECFA (Joint FAO/WHO Expert Committee on Food Additives), que determina que a Ingestão Diária Aceitável (IDA) do corante caramelo IV é $200 \mathrm{mg}$ por Kg de peso corpóreo (p.c.) por dia e a concentração residual de 4-MEI no corante Caramelo IV, estabelecida na especificação do JECFA, $250 \mathrm{mg} / \mathrm{kg}$ de corante (0,025\%), ou seja, o consumo de até 0,05 mg 4-MEI/Kg p.c. não representa uma preocupação toxicológica (Brasil, 2012).

A literatura relata possíveis efeitos tóxicos decorrentes do consumo do 4-MEI em ratos e camundongos, no entanto, nenhuma informação clara está disponível em relação aos efeitos genotóxicos ou citotóxicos de 4-MEI em humanos. Estudos realizados pelo National Toxicology Program dos Estados Unidos mostraram que o 4-MEI pode causar câncer de pulmão, fígado, tireoide e leucemia. Reconhecendo os estudos, a Agência de Proteção Ambiental da Califórnia classificou a substância como cancerígena e determinou que qualquer produto com concentração maior que 0,029 $\mathrm{mg}$ de 4-MEI por porção deve informar o possível risco na embalagem (National Toxicology Program, 2007). No Brasil, segundo o Instituto de Defesa do Consumidor (IDEC), isso significa dizer que, se levar em consideração uma porção de $100 \mathrm{~g}$ de determinado produto, a quantidade permitida no Brasil é quase 700 vezes maior que a permitida na Califórnia (Instituto Brasileiro de Defesa do Consumidor, 2019).

Um estudo de ingestão alimentar, realizado por Gama e Polônio (2018) que avaliaram rótulos de alimentos frequentemente consumidos por graduandos em Nutrição de uma Universidade pública do estado do Rio de Janeiro, mostrou que os corantes mais comumente encontrados nos produtos consumidos foram caramelo III e IV, urucum e carmim. O corante caramelo IV foi o que mais se destacou nos produtos consumidos pelos universitários (13,5\%) (Gama \& Polônio, 2018). 
Pode-se observar que o consumo de produtos que apresentam os corantes caramelos é bastante difundido no Brasil e os possíveis efeitos tóxicos desses compostos têm causado preocupação nos últimos anos. Tendo em vista o elevado consumo de alimentos industrializados e a potencial exposição em longo prazo do corante caramelo IV, bem como do seu subproduto 4-MEI, em diferentes faixas etárias, torna-se relevante o estudo dos dados disponíveis recentemente acerca da toxicidade do 4- MEI.

\section{Metodologia}

A metodologia deste trabalho foi elaborada de acordo com Cumpston \& Chandler (2020) e Moher et al. (2015). Esse trabalho foi elaborado a partir de uma revisão da literatura nas bases de dados PubMed, Science Direct e Lilacs, nos últimos 5 anos. A pesquisa foi realizada na língua inglesa e as palavras-chave utilizadas foram "caramel color IV, "caramel coloring $I V$ ", "caramel IV", "INS 150d", "4-methylimidazole" e "4-MEI", sendo utilizado o operador booleano "or" entre os termos. Após a busca, houve um retorno de 64 artigos na PubMed, 362 na Science Direct e 12 na Lilacs.

Como critérios de inclusão foram adotados: ensaios clínicos randomizados, casos-controle e estudos in vivo e in vitro. Foram utilizados como critérios de exclusão: duplicatas, estudos descritivos, estudos metodológicos e revisões. Inicialmente, foram encontrados 438 artigos, mas após a leitura dos títulos dos artigos, notou-se que alguns deles não preenchiam os critérios de inclusão adotados. Dessa forma, foram selecionados 27 artigos para a leitura do resumo e excluídos os que não diziam respeito ao propósito deste estudo. Após aplicação dos critérios de inclusão e exclusão, foram selecionados no total 8 artigos, a maior parte deles coincidiam em todas as bases de dados pesquisadas. A busca e seleção de artigos ocorreu entre os meses de dezembro de 2020 e janeiro de 2021.

\section{Resultados e Discussão}

O fluxograma de seleção dos artigos está apresentado na Figura 1. A busca inicial resultou em 438 artigos em 3 bases de dados e, após a aplicação dos critérios de elegibilidade, foram incluídos nesta revisão 8 estudos.

Figura 1 - Fluxograma da seleção dos estudos.

\begin{tabular}{|c|c|c|c|}
\hline$\frac{\text { PubMed }}{\mathrm{n}=64}$ & $\begin{array}{c}\text { Science Direct } \\
\mathrm{n}-362\end{array}$ & $\frac{\text { Lilacs }}{n-12}$ & Total $=438$ artigos \\
\hline & $\begin{array}{l}\text { Estudos selecionados e } \\
\text { incluidos na revisăo }(\mathrm{n}=8)\end{array}$ & & $\begin{array}{l}430 \text { artigos excluidos: } \\
\text { - } \quad \text { Duplicatas } \\
\text { - Estudos descritivos } \\
\text { - Estudos } \\
\text { - } \text { metodológicos } \\
\text { - Revisôes }\end{array}$ \\
\hline
\end{tabular}

Fonte: Autores.

Em relação à toxicidade do 4-MEI apresentada nos artigos selecionados, o Quadro 1 sintetiza estas principais informações. Entre os estudos analisados, $50 \%(\mathrm{n}=4)$ demonstraram algum efeito tóxico do 4-MEI em ratos ou camundongos e $50 \%(\mathrm{n}=4)$ não observaram efeitos tóxicos do 4-MEI em modelos experimentais. Todos as pesquisas selecionadas para esta revisão se tratavam de estudos experimentais (in vivo ou in vitro) e não foram encontrados ensaios clínicos randomizados ou casos-controle no período analisado. 
Quadro 1 - Descrição geral dos principais resultados encontrados nos estudos selecionados.

\begin{tabular}{|c|c|c|c|}
\hline Título & Autores & Tipo de estudo & Efeito tóxico \\
\hline $\begin{array}{l}\text { Multigenerational reproductive } \\
\text { assessment of 4-methylimidazol e } \\
\text { administered in the diet to Hsd: } \\
\text { Sprague Dawley SD rats }\end{array}$ & Behl et al. 2020 & $\begin{array}{l}\text { In vivo } \\
\text { (ratos) }\end{array}$ & $\begin{array}{l}\text { 4-MEI }(50-60 \mathrm{mg} / \mathrm{kg} \text { p.c./dia) } \rightarrow \\
\text { Toxicidade reprodutiva }\end{array}$ \\
\hline $\begin{array}{l}\text { Comparison of acute respiratory } \\
\text { epithelial toxicity for } 4- \\
\text { Methylimidazole and naphthalene } \\
\text { administered by oral gavage in } \\
\text { B6C3F1 mice }\end{array}$ & Kelty et al. 2020 & $\begin{array}{l}\text { In vivo } \\
\text { (ratos) }\end{array}$ & $\begin{array}{l}\text { 4-MEI }(150-300 \mathrm{mg} / \mathrm{kg} \text { p.c./dia) } \rightarrow \\
\text { Nenhum efeito tóxico em células } \\
\text { exócrinas bronquiolares }\end{array}$ \\
\hline $\begin{array}{c}\text { Metabolism of 4-methylimidazole } \\
\text { in Fischer } 344 \text { rats and B6C3F1 } \\
\text { mice }\end{array}$ & $\begin{array}{l}\text { Fennell et al. } \\
\quad 2019\end{array}$ & $\begin{array}{l}\text { In vitro e in vitro } \\
\text { (ratos e camundongos) }\end{array}$ & $\begin{array}{l}\text { 4-MEI }(50 \text { e } 150 \mathrm{mg} / \mathrm{kg}) \rightarrow \text { Nenhum } \\
\text { efeito tóxico em microssomas } \\
\text { hepáticos ou frações S-9 do pulmão }\end{array}$ \\
\hline $\begin{array}{c}\text { Genotoxic effects of } 4 \text { - } \\
\text { methylimidazole on human } \\
\text { peripheral lymphocytes in vitro }\end{array}$ & $\begin{array}{l}\text { Celik e Topaktas, } \\
2018\end{array}$ & $\begin{array}{c}\text { In vitro } \\
\text { (linfócitos humanos) }\end{array}$ & $\begin{array}{l}\text { 4-MEI }(0,6 \text { e } 0,75 \mathrm{mg} / \mathrm{mL}) \rightarrow \text { efeitos } \\
\text { genotóxicos e citotóxicos }\end{array}$ \\
\hline $\begin{array}{c}\text { Chronic intake of 4- } \\
\text { Methylimidazole induces } \\
\text { Hyperinsulinemia and } \\
\text { Hypoglycemia via Pancreatic Beta } \\
\text { Cell Hyperplasia and Glucose } \\
\text { Dyshomeostasis }\end{array}$ & $\begin{array}{l}\text { Rekha et al., } \\
2018\end{array}$ & $\begin{array}{l}\text { In vivo } \\
\text { (camundongos) }\end{array}$ & $\begin{array}{l}\text { 4-MEI }(0,032 \mathrm{mg} / \mathrm{kg} \text { p.c./dia }) \rightarrow \\
\text { alterações no metabolismo da } \\
\text { glicose e da insulina. Mas não foram } \\
\text { observados efeitos tóxicos }\end{array}$ \\
\hline $\begin{array}{l}\text { Evaluation of 4-Methylimidazole, } \\
\text { in the Ames/Salmonella Test Using } \\
\text { Induced Rodent Liverand Lung S9 }\end{array}$ & $\begin{array}{c}\text { Beevers e } \\
\text { Richard, } 2016\end{array}$ & $\begin{array}{l}\text { In vitro } \\
\text { (Salmonella) }\end{array}$ & $\begin{array}{l}\text { 4-MEI }(0,005 \text { a } 5 \mathrm{mg} / \mathrm{dia}) \rightarrow \\
\text { nenhuma toxicidade }\end{array}$ \\
\hline $\begin{array}{l}\text { The effects of 4-MEI on cell } \\
\text { proliferation, DNA breaking and } \\
\text { DNA fragmentation }\end{array}$ & $\begin{array}{l}\text { Tazehkand et al., } \\
2016\end{array}$ & $\begin{array}{l}\text { In vitro } \\
\text { (camundongos) }\end{array}$ & $\begin{array}{l}\text { 4-MEI }(0,3,0,45,0,6 \text { e } 0,75 \mathrm{mg} / \mathrm{mL}) \\
\rightarrow \text { Efeito citotóxico em células } 3 \mathrm{~T} 3- \\
\mathrm{L} 1 \text { e efeitos de necrose nas células } \\
\text { hepáticas }\end{array}$ \\
\hline $\begin{array}{l}\text { Assessment of chromosomal } \\
\text { aberration in the bone marrow } \\
\text { cells of Swiss Albino mice treated } \\
\text { by 4-methylimidazole }\end{array}$ & $\begin{array}{l}\text { Tazehkand et al., } \\
2016\end{array}$ & $\begin{array}{c}\text { In vitro } \\
\text { (camundongos) }\end{array}$ & $\begin{array}{l}\text { 4-MEI }(100,130 \text { e } 160 \mathrm{mg} / \mathrm{Kg} \text { p.c. }) \\
\rightarrow \quad \text { aumento de aberrações } \\
\text { cromossômicas e redução do índice } \\
\text { mitótico }\end{array}$ \\
\hline
\end{tabular}

p.c. $=$ peso corpóreo. Fonte: Autores.

Behl et al. (2020) realizaram uma avaliação da toxicidade reprodutiva em ratos, no qual múltiplas gerações foram expostas a 4-MEI na dieta na dosagem de 0,75, 2,5 e $5 \mathrm{mg} / \mathrm{g}$. Essa exposição foi associada a atrasos na separação prepucial e abertura vaginal, prejuízo no desempenho reprodutivo e histopatológicos na próstata, testículos e epidídimo, da prole, nas concentrações 2,5 e $5 \mathrm{mg} / \mathrm{g}$. O nível mais baixo observado de efeito adverso para toxicidade reprodutiva (com base na atrofia da próstata) e no desenvolvimento (com base em atrasos em separação prepucial e abertura vaginal) foi de $0,75 \mathrm{mg} / \mathrm{g}$, equivalente a aproximadamente 50-60 mg/kg p.c. (Behl et al., 2020). 
Celik e Topaktas (2018) investigaram os efeitos citotóxicos e genotóxicos de 4-MEI em linfócitos humanos. Para este propósito, linfócitos periféricos humanos foram tratados com quatro concentrações de 4-MEI $(0,3,0,45,0,6$ e 0,75 $\mathrm{mg} / \mathrm{mL}$ ). Ocorreu a troca de cromátides irmãs induzida por 4-MEI em linfócitos periféricos humanos nas três concentrações mais altas $(0,45,0,6$ e $0,75 \mathrm{mg} / \mathrm{mL})$ no período de $48 \mathrm{~h}$ de tratamento. Aberrações cromossômicas e micronúcleos foram observados em linfócitos periféricos humanos nas duas maiores concentrações de 4-MEI $(0,6$ e $0,75 \mathrm{mg} / \mathrm{mL})$ em períodos de tratamento de 24h e 48h. Os resultados desse estudo mostraram que 4-MEI apresenta efeitos genotóxicos e citotóxicos em linfócitos periféricos humanos.

Tazehkand et al. (2016) investigaram os efeitos do 4-MEI na proliferação celular e na quebra e fragmentação do DNA celular de ratos tratados com o 4-MEI. Neste estudo, a linhagem celular 3T3-L1 de camundongo foi tratada com 4-MEI nas concentrações de 0,3, 0,45, 0,6 e 0,75 mg/mL por períodos de 24 e 48 horas. As análises mostraram que 4-MEI inibiu significativamente a proliferação celular da linhagem celular 3T3-L1 na concentração mais alta por 24 horas e em todas as concentrações por 48 horas de tratamento. 4-MEI mostrou efeito citotóxico em células 3T3-L1, mas nenhum efeito na quebra de DNA. O ensaio de fragmentação de 4-MEI demonstrou efeitos de necrose nas células hepáticas dos camundongos.

Os mesmos autores supracitados também avaliaram os efeitos genotóxicos e citotóxicos do 4-MEI usando aberrações cromossômicas (ACs) e índice mitótico (IM) em camundongos albinos suíços. Nesta pesquisa, ACs e IM das células da medula óssea de camundongo foram analisados após o tratamento dos animais com 4-MEI (100, 130 e $160 \mathrm{mg} / \mathrm{kg}$ p.c.) em tempos de tratamento de $12 \mathrm{~h}$ e $24 \mathrm{~h}$. 4-MEI aumentou significativamente a porcentagem de ACs em todas as concentrações por $12 \mathrm{~h}$ e na concentração mais alta por períodos de tratamento de $24 \mathrm{~h}$. O 4-MEI na concentração máxima por $12 \mathrm{~h}$ e em todas as concentrações por 24h diminuiu o IM em comparação ao controle, demonstrando que o 4-MEI possui efeitos genotóxicos e citotóxicos (Tazehkand et al., 2016).

Kelty et al. (2020) não observaram nenhuma toxicidade de 4-MEI em células club (células exócrinas bronquiolares) após exposição aguda de doses de $150 \mathrm{mg} / \mathrm{kg}$ p.c. ou $300 \mathrm{mg} / \mathrm{kg}$ p.c. por gavagem oral. Cruzan et al. (2015) estudaram a hipótese de que 4-MEI poderia induzir tumor pulmonar em camundongos pelo mecanismo de ação do estireno. Tanto o estireno quanto o naftaleno são conhecidos por causar tumores de pulmão em camundongos por um modo de ação semelhante. Ambos compostos produzem aumentos na síntese de DNA (conforme medido pelo aumento de marcadores BrdU) e proliferação nos bronquíolos terminais desencadeada por metabólitos formados pela atividade do citocromo CYP2F2, que é encontrado em níveis excepcionalmente altos nas células $C l u b$ no pulmão de camundongos. Foram encontradas poucas evidências de citotoxicidade produzida pelo 4-MEI ou aumento da síntese de DNA e proliferação celular na região bronquiolar dos pulmões de camundongos B6C3F1 ou C57BL/6. Foi encontrado um pequeno aumento de marcadores BrdU entre camundongos machos expostos a 1,25 $\mathrm{mg} / \mathrm{g}$ de 4-MEI, não apresentando diferença estatisticamente significativa, em comparação com o aumento de 27 vezes produzido pelo estireno.

Fennell et al. (2019) investigaram o metabolismo in vitro em ratos e camundongos, comparado com o metabolismo in vivo. Foram administrados 50 e $150 \mathrm{mg} / \mathrm{kg}$ p.c. de 4-MEI em ratos (F-344) machos e fêmeas e camundongos (B6C3F1). Excretas e voláteis exalados foram coletados após 48 horas. Nenhum metabólito foi detectado no pulmão dos ratos ou camundongos e microssomas hepáticos ou frações S-9 do pulmão. A principal forma de eliminação do 4-MEI se deu pela urina, excreção pelas fezes foi contabilizada em 1,9-4,3\% e um pequeno percentual (1,3-1,7\%) foi eliminado na forma de $\mathrm{CO}_{2}$, praticamente nenhum (0,01-0,1\%) como voláteis exalados. De acordo com os resultados encontrados neste estudo, o metabolismo do 4-MEI pareceu semelhante nos modelos experimentais rato e camundongo.

Rekha et al. (2018) avaliaram o efeito do 4-MEI no metabolismo da glicose de camundongos que foram tratados com 0,032 $\mathrm{mg} / \mathrm{Kg}$ de peso corporal de 4-MEI por via oral, usando uma sonda por sete semanas continuamente. Todos os animais expostos a 4-MEI exibiram uma diminuição constante no nível de glicose no sangue, atingindo a condição hipoglicêmica após 
35 dias ( $\mathrm{p}<0,0001$ ), que prolongou-se até o final do experimento. Quase 50\% dos animais atingiram hipoglicemia grave (nível de glicose $<70 \mathrm{mg} / \mathrm{dL}$ ) no final do experimento. A ingestão de 4-MEI em camundongos suprime o nível de glicose circulatória ao elevar o catabolismo da glicose. Além disso, a análise histopatológica do pâncreas dos camundongos expostos a 4-MEI demonstrou hiperplasia de células beta pancreáticas induzida por 4-MEI o que levou a hiperinsulinemia. Observou-se também que a exposição crônica de 4-MEI não levou ao aumento do estresse oxidativo e à morte celular.

Beevers e Richard (2016) testaram a capacidade do 4-MEI para induzir mutação em cinco cepas padrão de Salmonella typhimurium pelo teste de Ames, utilizando rato induzido (F344/N), fígado de camundongo (B6C3F1) e pulmão S9 como fontes de metabolismo exógeno. O 4-MEI não causou toxicidade em nenhuma das cepas de Salmonella quando testadas em concentrações de 0,005 a $5 \mathrm{mg} / \mathrm{mL}$ na ausência ou presença do metabolismo exógeno de fígado ou pulmão de roedores S9, mostrando que o 4-MEI não é um composto genotóxico.

A ausência de padronização entre as dosagens dos compostos e dos modelos experimentais estudados foi um fator limitante na comparação dos resultados observados nos estudos avaliados. Além disso, os estudos que encontraram associação de 4-MEI a algum efeito tóxico ou alteração metabólica $(n=4)$ utilizaram dosagens acima da IDA. A IDA foi estabelecida em estudos mais antigos, sendo necessária sua revisão com base em estudos mais robustos, uma vez que observa-se um aumento crescente no consumo de alimentos industrializados que contém caramelo IV, consequentemente o 4-MEI, em suas composições.

Fierens et al. (2018) descreveram a ocorrência de 4-MEI em uma ampla variedade de produtos alimentícios $(\mathrm{n}=522)$ comprados no mercado belga e sua ingestão alimentar em consumidores belgas a partir de 15 anos. O 4-MEI estava presente em $22,4 \%$ dos alimentos investigados em concentrações de até $2,835 \mathrm{mg} / \mathrm{kg}$, sendo a ingestão alimentar média de 0,0004-0,0037 $\mathrm{mg} / \mathrm{kg}$ p.c./dia. Café e refrigerantes de cola foram os que mais contribuíram para a ingestão dietética desse composto na Bélgica.

Fuji et al. (2018) determinaram a quantidade de 4-MEI em Coca-Cola ${ }^{\circledR}$ e encontraram variações de 0,00018 a 0,00025 $\mathrm{mg} / \mathrm{mL}$. Xu et al. (2015) encontraram 4-MEI em refrigerantes e refrigerantes contendo o corante caramelo IV em variações de 0,00013 a 0,00034 mg/mL. Ratnayake et al. (2015) observaram variações de 0,0000097 a 0,000641 mg/mL de 4-MEI em diferentes refrigerantes de cola.

Cunha et al. (2016) avaliaram a presença de 4-MEI em diferentes tipos de café comercializados em Portugal. Em um total de 45 amostras de café analisadas, todas apresentaram o 4-MEI, com níveis que variaram de 0,136 a $1,411 \mathrm{mg} / \mathrm{kg} .{ }^{23} \mathrm{Os}$ níveis de 4-MEI observados são maiores que aqueles obtidos para refrigerantes de cola. Apesar de não ser adicionado corantes caramelos em cafés, o 4-MEI pode ser formado durante o processamento térmico dos grãos, bem como em outros alimentos submetidos a aquecimento, inclusive no preparo caseiro (Folmer et al., 2018).

Considerando o consumo de 4-MEI de até $0,05 \mathrm{mg}$ 4-MEI/kg p.c., estabelecido pelo JECFA, significa que uma pessoa adulta de $60 \mathrm{Kg}$ pode consumir, sem riscos à saúde, até $3 \mathrm{mg}$ de 4-MEI/dia, enquanto uma criança de $30 \mathrm{~kg}$ poderia consumir até 1,5 mg de 4-MEI/dia. Fazendo uma média de consumo com os estudos que quantificaram 4-MEI em refrigerantes de cola $(0,00026 \mathrm{mg} / \mathrm{mL})$, seria necessário o consumo de $11,5 \mathrm{~L} /$ dia de refrigerante de cola para um adulto e o consumo de 5,8 L/dia por uma criança para se atingir o risco toxicológico.

Faltam dados recentes da estimava real do consumo de refrigerantes, mas segundo dados da Pesquisa Nacional de Saúde do Escolar (PeNSE), realizada em 2009, dos adolescentes avaliados, 21,7\% relataram o consumo de refrigerantes diariamente (Instituto Brasileiro de Geografia e Estatística, 2009a). De acordo com a última Pesquisa de Orçamentos Familiares (POF) realizada entre 2008 e 2009 pelo Instituto Brasileiro de Geografia e Estatística (IBGE), a média do consumo per capita de refrigerantes por faixa etária, foi de 123,7 mL/dia para adolescentes, $98,2 \mathrm{~mL} /$ dia para adultos e 35,1 $\mathrm{mL} /$ dia para idosos (Instituto Brasileiro de Geografia e Estatística, 2009b). Isso significa que os adolescentes estariam consumindo em média 0,032 mg de 4MEI por dia, os adultos 0,03 mg/dia e os idosos 0,0091 mg/dia. Em nenhuma das situações a recomendação diária aceitável é ultrapassada. Dessa forma, tais concentrações de 4-MEI não apresentariam risco de toxicidade. No entanto, questiona-se a 
quantidade de 4-MEI presente na ingestão real de refrigerantes, tendo em vista que o consumo médio pode estar distante da ingestão de indivíduos que consomem muito acima da média, especialmente crianças, que poderiam alcançar mais facilmente a IDA estabelecida. Cabe ressaltar ainda, que a ingestão aceitável no Brasil é muito maior do que em outros países, como por exemplo na Califórnia, que estabeleceu que qualquer produto com concentração maior que $0,029 \mathrm{mg}$ de 4-MEI por porção deve informar o possível risco na embalagem (Brasil, 2012).

Epifânio et al. (2020) realizaram análise de série temporal do consumo de bebidas açucaradas, incluindo refrigerantes, por adultos no Brasil entre 2007 a 2014. Eles observaram que a prevalência de brasileiros que consomem refrigerantes em cinco ou mais dias da semana é elevada, cerca de um copo ou uma lata por dia (aproximadamente $300 \mathrm{~mL}$ ). Além disso, é preciso levar em consideração que pode se ingerir diversos alimentos que apresentam 4-MEI ao longo do dia, e não apenas refrigerantes a base de cola, como é muito citado pela literatura. O café, por exemplo, é um alimento com elevado conteúdo de 4-MEI, que está amplamente presente na alimentação dos brasileiros (Arruda et al., 2009). Dessa forma, a IDA poderia ser facilmente atingida e, até mesmo, ultrapassada, além disso, seria necessário avaliações mais abrangentes sobre os efeitos cumulativos da ingestão constante desse composto.

\section{Considerações Finais}

Com base nas contribuições dos estudos revisados, pode-se dizer que as evidências acerca da toxicidade do subproduto 4-MEI são divergentes, uma vez que as pesquisas encontraram tanto associações nulas quanto negativas associadas à sua exposição. Nenhum estudo demonstrou com clareza os possíveis mecanismos de ação tóxica deste composto na indução de tumores nos modelos estudados. Além disso, as concentrações de 4-MEI observadas nos estudos avaliados se encontraram acima da IDA.

Portanto, futuras pesquisas utilizando diferentes modelos experimentais devem ser realizadas para determinar o real impacto de diferentes dosagens de 4-MEI em humanos, além do efeito cumulativo de sua ingestão, bem como seus mecanismos de toxicidade e a real ingestão de alimentos que apresentam essa substância. Estudos longitudinais seriam interessantes para avaliar os reais impactos da ingestão crônica dessa substância.

\section{Referências}

Arruda, A. C., Minim, V. P. R., Ferreira, M. A. M., Minim, L. A., Silva, N. M., \& Soares, C. F. (2009). Justificativas e motivações do consumo e não consumo de café. Ciência e Tecnologia de Alimentos, 29(4), 754-763.

Ashurst, P. R., Hargitt, R., \& Palmer, F. (2017). Ingredients in Soft Drinks. In Soft Drink and Fruit Juice Problems Solved (2nd ed.), 29-66. Woodhead Publishing.

Beevers, C., \& Richard H., A. (2016). Evaluation of 4-Methylimidazole, in the Ames/Salmonella Test Using Induced Rodent Liver and Lung S9. Environmental and Molecular Mutagenesis, 57, 51-57.

Behl, M., Willson, C. J., Cunny, H., Foster, P. M. D., McIntyre, B., Shackelford, C., Shockley, K. R., McBride, S., Turner, K., Waidyanatha, S., \& Blystone, C. R. (2020). Multigenerational reproductive assessment of 4-methylimidazole administered in the diet to Hsd:Sprague Dawley SD rats. Reproductive Toxicology, 98, 1-19.

BeMiller, J. N. (2018). Carbohydrate Chemistry for Food Scientists (3rd ed.) 351-370.

Brasil, Agência Nacional de Vigilância Sanitária (ANVISA). (2012). Informe Técnico no. 48, de 10 de abril de 2012. Assunto: Esclarecimento sobre a segurança de uso do corante Caramelo IV - processo sulfito amônia (INS 150d).

Celik, R., \& Topaktas, M. (2018). Genotoxic effects of 4-methylimidazole on human peripheral lymphocytes in vitro. Drug and Chemical Toxicology, 41(1), $27-32$.

Codex Alimentarius. (2019). General standard for food additives codex stan 192-1995 (última atualização). 484.

Cumpston, M., \& Chandler, J. (2020). Chapter II: Planning a Cochrane Review. In: Higgins, J. P. T., Thomas, J., Chandler, J., Cumpston, M., Li, T., Page, M. J. \& Welch, V. A. (Eds.). Cochrane Handbook for Systematic Reviews of Interventions version 6.1 (updated September 2020).

Cunha, S. C., Senra, L., Cruz, R., Casal, S., \& Fernandes, J. O. (2016). 4-methylimidazole in soluble coffee and coffee substitutes. Food Control, 63, 15-20. 
Epifânio, S. B. O., Cardoso, J. A., Egito, R. C., Marinho, M., Maria, K., Brebal, M., \& Longo-silva, G. (2020). Análise de série temporal do consumo de bebidas açucaradas entre adultos no Brasil: 2007 a 2014. Ciência e Saúde Coletiva, 25(7), 2529-2540.

Fennell, T. R., Watson, S. L., Dhungana, S., \& Snyder, R. W. (2019). Metabolism of 4-methylimidazole in Fischer 344 rats and B6C3F1 mice. Food and Chemical Toxicology, 123, 181-194.

Fierens, T., Van Holderbeke, M., Cornelis, C., Jacobs, G., Sioen, I., De Maeyer, M., Vinkx, C., \& Vanermen, G. (2018). Caramel colour and process contaminants in foods and beverages: Part II - Occurrence data and exposure assessment of 2-acetyl-4-(1,2,3,4-tetrahydroxybutyl)imidazole (THI) and 4-methylimidazole (4MEI) in Belgium. Food Chemistry, 255, 372-379.

Folmer, D. E., Doell, D. L., Lee, H. S., Noonan, G. O., \& Carberry, S. E. (2018). A U.S. population dietary exposure assessment for 4-methylimidazole (4-MEI) from foods containing caramel colour and from formation of 4-MEI through the thermal treatment of food. Food Additives and Contaminants, 35(10), 18901910 .

Fujii, Y., Ding, Y., Umezawa, T., Akimoto, T., Xu, J., Uchida, T., \& Fujino, T. (2018). Detection and quantification of 4-methylimidazole in cola by matrixassisted laser desorption ionization mass spectrometry with Fe 2 O 3 nanoparticles on zeolite. Analytical Sciences, 34(2), 221-225.

Gama, D. N., \& Polônio, M. L. T. (2018). Corantes alimentares presentes em alimentos ultraprocessados consumidos por universitários. J. Res.: Fundam. Care. Online, 10(2), 310-317.

Instituto Brasileiro de Defesa do Consumidor (IDEC). (2019). Você sabe o que é Caramelo IV? https://idec.org.br/consultas/dicas-e-direitos/voce-sabe-o-quee-caramelo-iv

Instituto Brasileiro de Geografia e Estatística (IBGE). (2009a). Pesquisa Nacional de Saúde do Escolar.

Instituto Brasileiro de Geografia e Estatística (IBGE). (2009b). POF 2008-2009. Pesquisa de Orçamentos Familiares - Análise do Consumo Alimentar Pessoal no Brasil.

Kelty, J. S., Keum, C., Brown, V. J., Edwards, P. C., Carratt, S. A., \& Van Winkle, L. S. (2020). Comparison of acute respiratory epithelial toxicity for 4Methylimidazole and naphthalene administered by oral gavage in B6C3F1 mice. Regulatory Toxicology and Pharmacology, 116, 1-11.

Mateo-Fernández, M., Alves-Martínez, P., Río-Celestino, M. Del, Font, R., Merinas-Amo, T., \& Alonso-Moraga, Á. (2019). Food safety and nutraceutical potential of caramel colour class IV using in vivo and in vitro assays. Foods, 8(9).

Moher, D., Shamseer, L., Clarke, M., Ghersi, D., Liberati, A., Petticrew, M., Shekelle, P., Stewart, L. A., \& Group, P. (2015). Preferred reporting items for systematic review and meta-analysis protocols (PRISMA-P) 2015 statement. Systematic Reciews, 4(1), 1-9.

National Toxicology Program, N. T. P. (2007). Toxicology and carcinogenesis studies of 4-methylimidazole (Cas No. 822-36-6) in F344/N rats and B6C3F1 mice (feed studies). National Toxicology Program Technical Report Series, 535, 1-274.

Ratnayake, G., Halldorson, T., Bestvater, L., Tomy, G. T., \& Tomy, G. T. (2015). Determination of 4(5) -methylimidazole in carbonated beverages by isotopedilution liquid chromatography- tandem mass spectrometry. Food Additives \& Contaminants: Part A, 37-41.

Rekha, B., Velmurugan, G., Freddy, A. J., Anusha, S., Ramprasath, T., Karthik, K. V., Suresh, S., Kulshrestha, P., Mithieux, G., Lyon, A. R., Selvam, G. S., \& Ramasamy, S. (2018). Chronic intake of 4-Methylimidazole induces Hyperinsulinemia and Hypoglycaemia via Pancreatic Beta Cell Hyperplasia and Glucose Dyshomeostasis. Scientific Reports, 8(1), 1-13.

Smith, T. J. S., Wolfson, J. A., Jiao, D., Crupain, M. J., \& Rangan, U. (2015). Caramel Color in Soft Drinks and Exposure to 4-Methylimidazole: A Quantitative Risk Assessment. 1-13.

Tazehkand, M N, Moridikia, A., Hajipour, O., Valipour, E., Timocin, T., Topaktas, M \& Yilmaz, M. B. (2016). The effects of 4-MEI on cell proliferation, DNA breaking and DNA fragmentation. Bratislava Medical Journal, 117(7), 371-375.

Tazehkand, Mostafa Norizadeh, Topaktas, M., \& Yilmaz, M. B. (2016). Assessment of chromosomal aberration in the bone marrow cells of Swiss Albino mice treated by 4-methylimidazole. Drug and Chemical Toxicology, 39(3), 307-311.

Xu, X., Liu, D., Yu, S., Yu, P., \& Zhao, Z. (2015). Separation and determination of 4-methylimidazole, 2-methylimidazole and 5-hydroxymethylfurfural in beverages by amino trap column coupled with pulsed amperometric detection. Food Chemistry, 169, 224-229. 